\title{
Reviewing Contribution for Mitigating Routing Overhead and Adopting Signal Strength in MANET
}

\author{
Sachidananda S Joshi \\ Assistant Professor \\ Department of Information Science and Engeening \\ SDM College of Engineering and Technology \\ Dhavalgiri Dharwad-580001
}

\author{
Sangappa Ramachandra Biradar, Ph.D. \\ Professor \\ Department Of Information Science and \\ SDM College of Engineering and Technology \\ Dhavalgiri Dharwad-580001
}

\begin{abstract}
Routing is one of the crucial phenomenons in any networking principles. However, formulation and operation of the routing protocols are not so easy in dynamic topologies like mobile adhoc network. Since past decade there has been an evolution of various routing protocols in mobile adhoc network community that are claimed to be efficient by various researchers, it became important to understand their effectiveness. Hence, the proposed study chooses to understand and scale the effectiveness of the existing routing protocols in mobile adhoc network from routing overhead minimization and adoption of signal strength in enhancing route behavior. The study has discussed some of the significant contributions and interesting outcomes with support of discussion on precise research gaps of the existing literatures.
\end{abstract}

\section{Keywords}

Mobile Adhoc Network, Routing Protocol, Routing Efficiency, Routing Overhead, Signal Strength

\section{INTRODUCTION}

Mobile adhoc network is spontaneously gaining popularity owing to its advanced and autonomous communication system. Every system in mobile adhoc network is allowed to move freely in any course, and will in this way transform its connections to different gadgets habitually. Each must forward traffic unrelated to its own particular utilization, and along these lines be a switched. The essential test in building a mobile adhoc network is preparing every gadget to consistently keep up the data needed to legitimately course activity. Such systems may work without anyone else's input or may be associated with the bigger Internet. They may contain one or numerous and diverse transceivers between mobile nodes. This results in an exceedingly rapid, self-ruling topology. Mobile adhoc network are a sort of Wireless specially appointed system that typically has a routable systems administration environment on top of a Link Layer adhoc network. Mobile adhoc network comprises of a peer-to-peer, autonomous, selfhealing system in contrast to a mesh system has a central controller. The area of mobile adhoc network is always associated with the ongoing issues of communication, intermittent link breakage, sub-standard quality of service, energy issues, bandwidth issues, etc. Out of all the issues, this paper primely discusses about the issues that arises from the routing overhead. One of the root cause of all these issues are mainly the dynamic topology of mobile adhoc network, which is also responsible of intermittent link breakage.

From more than a decade there has been a considerable research activity towards mechanizing an effective communication in Mobile Adhoc Network (MANET). With a volume of literatures being published almost in every year, the research community has evidently witnessed the consolidated issues in MANET, out of which effective and standardized routing is yet the unsolved and benchmarked. The significant and sincere effort of standardizing the routing protocols is done by MANET working group, who have published more than 55 RFC (Request of Comment) out of which 26 RFCs are no more in use, 21 RFCs are published, and 6 RFC being currently active [1]. Using mature components from previous work on experimental reactive and proactive protocols, the working groups have develop two Standards track routing protocol specifications e.g. Reactive MANET Protocol (RMP) and Proactive MANET Protocol (PMP). Enough studies focusing on the routing techniques have not be totally successful evolving out with benchmarked result owing to the dynamic topology and decentralized nature of the MANET environment. The uncertainty in node location in the mobility model has caused serious challenges in research to come up with potential algorithm that can mitigate the effects of imprecise routing behavior in MANET. The routing in important part of MANET as imprecise or inefficient routing behavior causes series Quality of Service as well as potential security threats. This research proposal entire concentrates on better communication establishment using routing protocol considering routing overhead, which is less explored topic in MANET. All the problems of the MANET are caused owing to the dynamic topology of MANET as well as the resource constraint. Because of this issue, nodes frequently perform transmission of control message with unnecessary flooding (or overhead) in the network thereby causing the routing overhead in MANET. The design of novel routing protocol that can mitigate the control overhead in MANET is extremely critical for better communication establishment in MANET. Because of this problem, MANET frequently encounters intermittent link breakage that leads to re-transmission leading to further overhead of routing protocol. This phenomenon has extremely adverse effect on Quality of Service parameters like (delay, throughput, and packet delivery ratio). Hence, minimization of control overhead in MANET without affecting the quality of potential routing behavior in MANET is considered as the problem identified for the proposed study.

\section{ROUTING PROTOCOL IN MANET}

The routing protocol in mobile adhoc network is responsible for the positive operation of the communication model. However, defining routing protocols in dynamic topology is never an easy task and it calls for proper understanding of their functionalities. Basically routing protocols in Mobile Adhoc Network is of three types e.g. i) Reactive, ii) Proactive, and iii) Hybrid type. The elaborate review of literature done by Raut et al. [2] most recently have descriptively discussed all the routing applicable in mobile adhoc network. Hence, a brief overview of the major taxonomies are described as follows: 


\subsection{Reactive Protocol}

This is one of the frequently used Routing protocol in Mobile Adhoc Network, which is also known as on-demand protocols. Such protocols, although, don't maintain the network topology information, but explicitly finds the route between the destination and source mobile nodes whenever it is required. Examples of such protocols are Adhoc on Demand Distance Vector (AODV) [3] and Dynamic Source Routing (DSR) [4]. Interestingly, such protocols never exchange any routing information periodically. It was found that time delay in such protocols are quite higher as compared to proactive protocols as the routes are estimated when it is needed.

\subsection{Proactive Protocol}

This is another frequently adopted routing protocol in studying mobile adhoc network. This protocol is also called as table driven routing protocol. Example of such protocol is Destination Sequence Distance Vector or commonly known as DSDV [5]. Such protocol ensures that every mobile node should retain maximum topological information as required in the form of routing table. The entire network is usually flooded with routing information and it commonly uses path finding technique to evaluate the needed path to the destination mobile node. One of the advantages of this protocol is packet forwarding mechanism, which is quite better and faster compared to reactive protocols. However, this protocol suffers from routing overhead as all the routes have to be distinctively segregated before performing packet transmission. Another advantage of this protocol is minimized latency as the routes are maintained all the times.

\subsection{Hybrid Protocol}

It can be seen that both reactive and proactive protocol have its own advantages and disadvantages, hence, this type of protocol is formulated based on the potential advantage characteristics of both reactive and proactive routing protocol. This protocol ensures that mobile nodes within certain distance from each other are said to be within the routing zone of a given mobile node. The hybrid technique adopts table driven when it is required to perform routing within such area of routing zone and adopts on demand technique for the nodes located beyond routing zone. The hybrid protocol also updates the routing table of active destinations that would drastically minimize the overhead as well as delay to enhance the network performance in mobile adhoc network. One good example of hybrid protocol is Zone Routing Protocol (ZRP) [6].

\section{EVALUATION PARAMETERS}

The prime purpose of this paper is to understand the significant contribution of various researchers in the past in relation to efficient routing protocol in mobile adhoc network. However, it was seen that various authors chooses various evaluation parameters to test and justify the effectiveness of their discussed protocols. The most common evaluation parameters as per the findings of this manuscript can be broadly categorized into performance and Quality of Service (QoS) parameters.

\subsection{Performance Parameters}

These types of evaluation parameters are responsible for finding the algorithm effectiveness to the overall performance of the network system in mobile adhoc network. Some of the significant performance parameters used by the researchers till date are:

- Throughput: This is the parameter related to the channel capacity. It is defined as the maximum possible delivery of the messages over the channel. It is usually measured in bits per second

- Routing Overhead: It is defined in terms of number of control packets need to be sent for the route discovery as well as route maintenance so as to send data packets.

- Average Delay: it is defined as the time taken by the packet to reach from source to destination. It is measured in seconds. It is also known as end to end delay.

- Packet Delivery Ratio: It is defined as the ratio of incoming data packets to the received data packets. It can be understood that AODV has the better packet delivery ratio from the result of throughput.

- Scalability: It is defined as the performance of routing protocols in presence of large number of nodes.

\subsection{QoS Parameters}

The applications of the mobile adhoc network could have different needs and so the services that are required by them. Hence qualities of service (QoS) parameters sometimes differs and are specific to case to case in mobile adhoc network. It can be understood by citing a simple example. While working on multimedia streaming application in mobile adhoc network, the appropriate QoS parameters will be channel capacity, time, energy, likelihood of packet loss, jitter (or latency), communication overhead, scalability, and route acquisition delay. However, for hardcore military application, availability of the network is the sole QoS factor required. Some other conjoining parameters fall in this category are processing energy, buffer, and residual energy too. Some of the frequently adopted QoS parameters in prior studies are as follows:

- Time Complexity: It is the maximum time that can elapse between the moment when the last topology change occurs and the moment at which all the routers have final shortest path and distance to all other routers.

- Delay: It is the time elapsed from the departure of a data packet from the source node to the arrival at the destination node, including queuing delay, switching delay, propagation delay, etc.

- Jitter: It is generally referred to as variations in delay, despite many other definitions. It is often caused by the difference in queuing delays experienced by consecutive packets.

- Scalability: It is the ability of a computer application or product (hardware or software) to continue to function well when it (or its context) is changed in size or volume in order to meet a user need.

- Packet Loss Rate: It is the percentage of data packets that are lost during the process of transmission. 
Table 1: Pattern of some significant evaluation parameters in routing protocols of MANET

\begin{tabular}{|l|l|l|l|}
\hline \multicolumn{1}{|c|}{ Parameter } & \multicolumn{1}{|c|}{ Table Driven(Proactive) } & Demand Driven(Reactive) & \multicolumn{1}{|c|}{ Hybrid } \\
\hline Energy Requirement & High & Low & Medium \\
\hline Bandwidth requirement & High & Low & Medium \\
\hline Control Overhead & High & Low & Medium \\
\hline Scalability & Up to hundred nodes & Up to few hundred nodes & $\begin{array}{l}\text { Designed for up to 1000 or more } \\
\text { nodes }\end{array}$ \\
\hline Communication Overhead & High & Low & Medium \\
\hline
\end{tabular}

\section{WORK IN ROUTING OVERHEAD}

In Mobile adhoc network, the mobile nodes very often change their location owing to dynamic topology within the network. Because of this phenomenon, it gives rise to some stale routes that are generated in the routing table finally leading to unnecessary routing overhead in mobile adhoc network. It is found that routing overhead arises owing to the control message dissemination process (RREQ, RREP, RACK, and RERR) in the dynamic topology of MANET. It was also seen that conventional reactive routing protocols generate a massive amount of routing traffic by simply flooding the while network area at the time of route discovery process. Even after known this flaw in reactive protocols, it was still found that a researcher very often considers AODV for benchmarking their work and associated outcomes. Most recently, the problem of minimizing routing protocols has attracted the attention of various researchers for ensuring optimal communication performance in mobile adhoc network. Therefore, a good routing protocol should have better management of routing table to deal with problems related to routing overhead. In the past decade, there are some studies which were found to mitigate routing overhead in mobile adhoc network.

La and Seo [7] have studied routing overhead due to location information collection and retrieval in mobile ad-hoc networks employing geographic routing with no hierarchy. The outcome of the study was evaluated with overhead $(n \log (n))$ to be found minimum. Er and Seah [8] have presented an extension of a typical MANET routing protocol that integrates an adaptive clustering mechanism and show that it is able to significantly reduce the communications overheads of routing protocols, thus paving the way for greater scalability. Jacquet and Viennot [9] have proposed a study of protocol overheads in mobile adhoc network.

Manjula and Santhosh [10] have proposed a rebroadcast delay to determine rebroadcast order. it combines the advantages of neighbor coverage knowledge and probabilistic mechanism, it significantly decrease the number of retransmissions to reduce the routing overhead and also to improve the routing performance. Sekhar et al. [11] have described the impact of routing overhead in a real-time-time MANET environment with suitable scenarios. And also suggested some methods to reduce the routing overhead over the network such that to improve the Quality of Service (QoS) routing in MANETS. Preetha et al. [12] study the issues in route discovery process in AODV protocol for MANET focusing on flooding of route request. This paper suggests a new approach to reduce the routing overhead during the route discovery phase. Yadav and Saxena [13] examined the performance of AODV and OLSR by varying different simulation parameter and measuring the performance metrics such as Packet Delivery Ratio, Average Delay, and Routing overhead. Patil et al. [14] proposed a Novel Rebroadcast Technique for Reducing Routing Overhead in Mobile Ad Hoc Networks. A new scheme has been proposed to dynamically calculate the rebroadcast delay, which is used to determine the forwarding order and more effectively exploit the neighbor coverage knowledge. Sindhuja and Vidhya [15] have used probabilistic rebroadcast algorithm to calculate the Covered Neighbor set and uncovered Neighbor set for broadcasting. Broadcasting based on probabilistic rebroadcast algorithm can effectively discover the route by using the additional coverage ratio and connectivity factor. Simulation results are demonstrated using NS-2 Simulator. From these results, the proposed system significantly decreases the number of retransmissions, routing overhead and increases the routing performance. Kure and Jain [16] have used probabilities rebroadcast routing protocol to overcome the problem neighbor coverage. Simulation result shows that the NCPR protocol generates less redundant rebroadcast traffic than flooding. Because of less redundant rebroadcast, neighbor coverage based Probabilistic rebroadcast Protocol mitigates the network collision and contention, so as to decrease end to end delay and increase packet delivery ratio.

Hence, it can be seen that majority of the prior work has been using probabilistic algorithm and rebroadcast technique as the mean to reduce the routing overhead in mobile adhoc network. Table 2 will highlight the in-depth studies of the significant contribution of prior researchers as well as limitations found in their study.

Table 2: Review of Work done in Routing Overhead Minimization in MANET

\begin{tabular}{|l|l|l|l|l|}
\hline Authors & Techniques & Performance Parameters & $\begin{array}{l}\text { Routing Protocol } \\
\text { Compared With }\end{array}$ & Inference \\
\hline La \& Seo [7] & Flat Geographic routing & Routing overhead & $\begin{array}{l}\text { Proactive and } \\
\text { Reactive } \\
\text { Geographic Routing }\end{array}$ & $\begin{array}{l}\text { Pros: Substantial reduction of } \\
\text { routing overhead } \\
\text { Cons: QoS parameters not } \\
\text { evaluated }\end{array}$ \\
\hline Er \& Seah [8] & Adaptive Cluster-based & $\begin{array}{l}\text { End-to-end delay, control } \\
\text { message, packet delivery } \\
\text { ratio }\end{array}$ & AODV & $\begin{array}{l}\text { Pros: Addresses scalability } \\
\text { issues } \\
\text { Cons: Energy efficiency not } \\
\text { evaluated. }\end{array}$ \\
\hline
\end{tabular}




\begin{tabular}{|c|c|c|c|c|}
\hline $\begin{array}{l}\text { Jacquet \& } \\
\text { Viennot [9] }\end{array}$ & $\begin{array}{l}\text { Multiple Scenarios } \\
\text { investigation }\end{array}$ & Tolerance, flooding rate & OLSR, AODV & $\begin{array}{l}\text { Pros: Tested on multiple } \\
\text { scenarios } \\
\text { Cons: Effective benchmarking } \\
\text { missing }\end{array}$ \\
\hline $\begin{array}{l}\text { Manjula \& } \\
\text { Santhosh [10] }\end{array}$ & $\begin{array}{l}\text { NCPR (Neighbor } \\
\text { Coverage-based } \\
\text { Probabilistic Rebroadcast) } \\
\text { Protocol }\end{array}$ & $\begin{array}{l}\text { Packet delivery ratio, } \\
\text { average end-to-end delay }\end{array}$ & -Nil- & $\begin{array}{l}\text { Pros: -Nil- } \\
\text { Cons: No discussion on } \\
\text { outcomes \& implementation } \\
\text { scenarios }\end{array}$ \\
\hline $\begin{array}{l}\text { Sekhar et al. } \\
{[11]}\end{array}$ & $\begin{array}{l}\text { NCPR (Neighbor } \\
\text { Coverage-based } \\
\text { Probabilistic Rebroadcast) } \\
\text { Protocol }\end{array}$ & $\begin{array}{l}\text { Packet delivery ratio, } \\
\text { average end-to-end delay }\end{array}$ & -Nil- & $\begin{array}{l}\text { Pros: -Nil- } \\
\text { Cons: No discussion on } \\
\text { outcomes \& implementation } \\
\text { scenarios }\end{array}$ \\
\hline $\begin{array}{l}\text { Preetha et al. } \\
\text { [12] }\end{array}$ & Probabilistic Approach & Connectivity index & AODV & $\begin{array}{l}\text { Pros: Minimize Flooding } \\
\text { overhead, less computational } \\
\text { complexity } \\
\text { Cons: No discussion of } \\
\text { benchmarked outcomes or } \\
\text { algorithm efficiency. }\end{array}$ \\
\hline $\begin{array}{l}\text { Yadav \& } \\
\text { Saxena [13] }\end{array}$ & $\begin{array}{l}\text { Investigational study on } \\
\text { AODV and OLSR }\end{array}$ & $\begin{array}{l}\text { Packet delivery ratio, end- } \\
\text { to-end delay, routing } \\
\text { overhead }\end{array}$ & AODV, OLSR & $\begin{array}{l}\text { Pros: Simple Approach } \\
\text { Cons: Not applicable in Large } \\
\text { Scale MANET }\end{array}$ \\
\hline Patil et al. [14] & Rebroadcast Technique & $\begin{array}{l}\text { Packet delivery ratio, } \\
\text { routing overhead, random } \\
\text { packet loss, delay, number } \\
\text { of nodes }\end{array}$ & NCPR, AODV & $\begin{array}{l}\text { Pros: NCPR found better than } \\
\text { AODV } \\
\text { Cons: Not applicable in Large } \\
\text { Scale MANET }\end{array}$ \\
\hline $\begin{array}{l}\text { Sindhuja \& } \\
\text { Vidhya [15] }\end{array}$ & Rebroadcast Technique & $\begin{array}{l}\text { Throughput, routing } \\
\text { overhead, packet drop }\end{array}$ & AODV & $\begin{array}{l}\text { Pros: Reduces network } \\
\text { collision \& contention } \\
\text { Cons: Doesn't address link } \\
\text { failure }\end{array}$ \\
\hline $\begin{array}{l}\text { Kure \& Jain } \\
{[16]}\end{array}$ & Rebroadcast Technique & $\begin{array}{l}\text { End-to-end delay, packet } \\
\text { delivery ratio, routing } \\
\text { overhead, node density }\end{array}$ & $\begin{array}{l}\text { NCPR, LBR, } \\
\text { AODV }\end{array}$ & $\begin{array}{l}\text { Pros: NCPR performs better } \\
\text { than LBR \& AODV } \\
\text { Cons: Energy efficiency not } \\
\text { discussed, algorithm } \\
\text { efficiency not discussed, } \\
\text { reliability on large scale } \\
\text { MANET is also not discussed. }\end{array}$ \\
\hline
\end{tabular}

\section{WORK IN SIGNAL STRENGTH}

Some of the studies explored while collecting data for understanding the alternative techniques used in addressing the routing effectiveness in mobile adhoc network is by using signal strength.. Discovery of Service in Mobile Adhoc Networks is an imperative piece of acknowledgment towards administration access whenever, anyplace. On the other hand, it comprises of noteworthy difficulties than in conventional frameworks of distributed system in mobile adhoc network, since administration disconnectivity will lead to network failure. The fundamental criteria for assessing an administration revelation plan is the viability with which: (1) service customers can discover an service provider and (2) the service provider will effectively convey the requested service. Since associations could be broken with nodes moving, the most imperative variable influencing service delivery achievement is the characteristics of remote associations along the administration way between administration supplier and requester. Integration might be resolved as per the relative displacement of the geographic positions of the mobile nodes. Then again, obtaining geographic position is a part of client's extravagance and will definitely include some significant pitfalls. From majority of the studies, it was found that one approach to get (topographical) position is by utilizing GPS. However GPS is an additional equipment and experiences poor signs in indoor situations. An alternate path is by measuring relative areas from altered, position-known base stations Therefore, "land nearness" is a wasteful and inadequate means for inferring network. Two components influencing connection quality are signal strength (SS) and sign to noise ratio (SNR).

Amid signal transmission, the transmitter sends the signal with certain transmission power. Subject to substantial scale and little scale fading, the signal arrives at the destination with certain energy, alongside the impedance from background noise and different parties who share the same band. Every receiver node has a receiver sensitivity, which is the energy of the weakest signal that could be dependably heard and demodulated by the destination node, and a threshold Signal to Noise Ratio, characterized as the base received power contrast between the signal and the noise for the recipient to have the capacity to get effectively. In this way, signal transmission succeeds just if the received signal fulfills both the receiver sensitivity and the SNR threshold. Both SS and SNR of a receiver data packet could be obtained from the network card driver. Signal quality has additionally been proposed as a metric for selecting dependable courses in directing conventions for versatile specially appointed systems. The measurements utilized by prior authors is the normal signal quality and route steadiness, while in some other studies, the researchers recommended a SNR-based neighbor choice for taking care of inconsistent connections. These methodologies use SS to show solid or weaker channels, without determining any movement tendency. Hence, it is believed that usage of Signal could be possibly used in improving the routing performance in a very challenging dynamic topology of mobile adhoc network. Table 3 will highlight some of the significant studies that claimed to adopt signal based strategies to improve routing performance of mobile adhoc network. 
Table 3: Review of Work Done in Using Signal Strength in Route Optimization in MANET

\begin{tabular}{|c|c|c|c|c|}
\hline Authors & Techniques & $\begin{array}{l}\text { Performance } \\
\text { Parameters }\end{array}$ & $\begin{array}{l}\text { Routing Protocol } \\
\text { Compared With }\end{array}$ & Inference \\
\hline Manjhi \& Patel [17] & $\begin{array}{l}\text { Received Signal } \\
\text { Strength (RSS) }\end{array}$ & $\begin{array}{l}\text { End-to-end delay, } \\
\text { packet delivery ratio, } \\
\text { throughput }\end{array}$ & AODV & $\begin{array}{l}\text { Pros: cumulatively Better than } \\
\text { AODV } \\
\text { Cons: less effective benchmarking } \\
\text { to prove reliability }\end{array}$ \\
\hline $\begin{array}{l}\text { Srinivasan \& } \\
\text { Kamalakkannan [18] }\end{array}$ & $\begin{array}{l}\text { Signal Strength \& } \\
\text { Energy Awareness }\end{array}$ & $\begin{array}{l}\text { End-to-end delay, } \\
\text { mobility, energy, control } \\
\text { overhead, packet } \\
\text { delivery ratio }\end{array}$ & DSR, SSA & $\begin{array}{l}\text { Pros: Better energy preservation, } \\
\text { DSR better than SSA } \\
\text { Cons: Not applicable to large scale } \\
\text { MANET, algorithm efficiency not } \\
\text { discussed }\end{array}$ \\
\hline Chin et al. [19] & $\begin{array}{l}\text { Investigational } \\
\text { techniques on AODV } \\
\text { \& DSDV based on } \\
\text { signal strength }\end{array}$ & Energy, Signal Quality & AODV, DSDV & $\begin{array}{l}\text { Pros: Effectively not discussed } \\
\text { about the benefits } \\
\text { Cons: Link stability issues not } \\
\text { addressed, Benchmarking } \\
\text { effectiveness not discussed with } \\
\text { enough evidence }\end{array}$ \\
\hline Muthusenthil [20] & $\begin{array}{l}\text { Signal based } \\
\text { geographic routing }\end{array}$ & $\begin{array}{l}\text { Location error rate, } \\
\text { packet drop, end-to-end } \\
\text { delay }\end{array}$ & GPSR & $\begin{array}{l}\text { Pros: Enhanced security } \\
\text { Cons: Effective benchmarking not } \\
\text { done }\end{array}$ \\
\hline Lu et al. [21] & $\begin{array}{l}\text { Anti-localization } \\
\text { anonymous routing } \\
\text { based on signal } \\
\text { strength }\end{array}$ & Human mobility & $\begin{array}{l}\text { Epidemic routing, } \\
\text { delivery ratio }\end{array}$ & $\begin{array}{l}\text { Pros: Provide anonymity } \\
\text { Cons: QoS factors not discussed, } \\
\text { algorithm efficiency not discussed. }\end{array}$ \\
\hline Hajj et al. [22] & $\begin{array}{l}\text { Dominating set-based } \\
\text { routing using RSS }\end{array}$ & $\begin{array}{l}\text { Backbone Size, Average } \\
\text { number of Hops, } \\
\text { network stretch }\end{array}$ & $\begin{array}{l}\text { Cardei's approach } \\
\text { [23] } \\
\text { Alzoubi's } \\
\text { approach [24] }\end{array}$ & $\begin{array}{l}\text { Pros: Better time \& space } \\
\text { complexity } \\
\text { Cons: Order of complexity not } \\
\text { evaluated, QoS parameters not } \\
\text { evaluated }\end{array}$ \\
\hline Haldkar \& Patil [25] & $\begin{array}{l}\text { Received Signal } \\
\text { Strength Indication } \\
\text { (RSSI) }\end{array}$ & $\begin{array}{l}\text { Node velocity, delay, } \\
\text { frequency, RSSI } \\
\text { charecteristics, PSNR }\end{array}$ & -Nil- & $\begin{array}{l}\text { Pros: Effective bandwidth } \\
\text { utilization } \\
\text { Cons: No benchmarking }\end{array}$ \\
\hline Khalfallah [26] & $\begin{array}{l}\text { Signal based } \\
\text { propagation model }\end{array}$ & $\begin{array}{l}\text { Throughput, Received } \\
\text { rate, }\end{array}$ & $\begin{array}{l}\text { Noisy shadowing } \\
\text { model }\end{array}$ & $\begin{array}{l}\text { Pros: Best works in VANET } \\
\text { system } \\
\text { Cons: QoS parameters not } \\
\text { evaluated }\end{array}$ \\
\hline Djahel [27] & $\begin{array}{l}\text { RSSI based congestion } \\
\text { control scheme }\end{array}$ & $\begin{array}{l}\text { Beacon delivery ratio, } \\
\text { delay, reception ratio }\end{array}$ & -Nil- & $\begin{array}{l}\text { Pros: Controls congestion for ITS } \\
\text { Cons: Not evaluated over large } \\
\text { network, no effective } \\
\text { benchmarking }\end{array}$ \\
\hline Bhanumathi [28] & $\begin{array}{l}\text { RSS based } \\
\text { overhearing and } \\
\text { rebroadcast reduction }\end{array}$ & $\begin{array}{l}\text { Delay, energy, number } \\
\text { of nodes, packet } \\
\text { delivery ratio }\end{array}$ & RandomCast [29] & $\begin{array}{l}\text { Pros: Better power saving } \\
\text { Cons: Not efficient delay is } \\
\text { accomplished }\end{array}$ \\
\hline Mukilan [30] & $\begin{array}{l}\text { Data Replication } \\
\text { Algorithm based on } \\
\text { energy and RSS }\end{array}$ & $\begin{array}{l}\text { Mobility, data } \\
\text { availability ratio, energy } \\
\text { consumption, delay, } \\
\text { throughput, delay }\end{array}$ & $\begin{array}{l}\text { Greedy Data } \\
\text { Replication } \\
\text { Algorithm }\end{array}$ & $\begin{array}{l}\text { Pros: Minimum energy } \\
\text { consumption } \\
\text { Cons: Work more focused on } \\
\text { energy efficiency, less evidence of } \\
\text { algorithm reliability }\end{array}$ \\
\hline
\end{tabular}




\section{RELATED WORK}

The most challengeable problem of MANETs is how to adapt the topology changing that affects the performance of the network. Due to changeable topology, routes from sources to destinations may be suddenly broken and nodes have to discover other available routes to deliver data. Research direction in these problems has been recently evolved in the study conducted by $\mathrm{Vu}$ and Kwon [31]. The authors have proposed a mobilityassisted on-demand routing algorithm for mobile ad hoc networks in the presence of location errors by adopting the Kalman filter to estimate accurate locations and consider route confidence in discovering routes. The advanced research direction of MANET is VANET, where the sincere attempt to investigate the routing overhead was addressed. One of such significant study was conducted by Poma et al. [32] who have applied machine learning algorithms to reduce network overhead by discriminating the worst intermediate nodes for the transmission of copies considering VANET environment. Investigation on location services and attempt to evaluate overhead was found in the study of Yang et al. [33] who have proposed a lightweight location service protocol oriented towards group motion. Routing was also studied using decision theory as evident in the work of Mezher et al. [34] have designed a routing scheme to dynamically select the forwarding paths using a gametheoretic approach over a multipath routing protocol. Kiwior and lam [35] have presented an evaluation of MANET protocol performance for an Airborne Network. The proactive protocols provide more consistent performance in terms of delay, which makes them more appropriate for real time applications. In addition, the overhead costs of proactive protocols are also more consistent which can help in planning network load. It remains to be seen if these protocols provide an advantage when the scenario becomes more complex with additional radio link(s), traffic and nodes. $\mathrm{Xu}$ et al. [36] presented an analytical framework to evaluate the behavior of generic reactive and proactive protocols in MANET.

Use of optimization principle is found the work done by Correia and Vazao [37] who have presented an improved version of the ACO framework, named as Simple Ant Routing Algorithm (SARA) that aims at reducing the overhead, by using a new route discovery technique, based on the concept of Control Neighbor Broadcast (CNB). The CNB allows SARA to control the control packets flooding level in the network. However, this flooding mechanism as the disadvantage of increase the time required to discover a route. Liu and Cheng [38] have presented a geometric routing -Local Tree based Greedy Routing for mobile ad-hoc Networks for overcoming shortcomings caused by planarization errors of previous geometric routing protocols. Quispe and Galan [39] discusses which of the routing strategies for mobile MANETs: proactive, reactive or hierarchical, has a better performance in such scenarios. By selecting a real urban area for the emergency and rescue scenario, the density of nodes has been computed and the mobility model needed for the validation study of AODV, DSDV and CBRP in the routing model. Ghosh et al. [40] have proposed a mobility framework to achieve this macrolevel abstraction of orbital movement. However, till date none of the studies are yet standardized for benchmarking highlighting an open-issue of research to solve the routing overhead problems in MANET.

\section{RESEARCH GAP}

The prior sections have discussed various strategies adopted by the researchers to overcome the performance and efficiency issues in mobile adhoc network, out of which routing overhead and signal strength have been studied explicitly. It can be found that in majority of the studies, the prior researchers have not discussed much about the routing overhead. Work towards the issues of routing overhead is considerable less and less effective too. The authors are not found to illustrate what is the extent of the required routing information to be obtained to what is the extent of the network resources to be required at the time of routing to accomplish their claimed network resources. There is also very less work towards addressing scalability issues in mobile adhoc network to explore the technique of measuring them (e.g. channel capacity etc. It was also seen that majority of the researchers have adopted AODV directly or enhanced it and used it for their study inspite of the knowing disadvantages of AODV. Adoption of AODV seems to become a trend of benchmarking by the researcher by some unknown reason, which is not properly justified by any of the studies discussed in Table 1 or Table 2. The benefits of using the enhanced version of AODV that can actually solve various issues by deploying selective route cache mechanism for the purpose of performing route discovery process has been realized. Such studies [17][19] are found to adopt the enhanced version of AODV that has been standardized in their work. However, closer look into the result obtained by them have critical problems in packet delivery ratio using AODV. Although AODV performs better for extended duration of traffic as compared to other routing protocols, but AODV have some disadvantages too that are not addressed by any of the authors discussed in this study. The likelihood of stale routes are very high using AODV as the node's transmission rate my differ widely and can alter dynamically from one to another node. Also, it can be seen that majority of the studies were implemented on small scale network, for which reason, when the network size will increase, there is a higher possibility that their performance factors will also decrease positively. It has been strongly debated that AODV is just based on assumptions of node cooperation, which is not the same in reality. Therefore, perceptions of the prior researcher to adopt AODV for improving the network performance or for benchmarking purpose should be deliberately change. Some of the studies like [19] have used DSDV for improving the performance of routing protocol in mobile adhoc network. It is to be highlighted that the significant flaws of DSDV adoption that it doesn't sustain higher traffic load as well as delay in large scale mobile adhoc network. It is meant to support only small scale network. It has been also explored that another frequently adopted routing protocol is DSR [19] even knowing the fact that in DSR, every mobile node should spend lot of processing time on any received control data, even if it is not from the actual recipient node. Hence, future researcher must think twice before choosing either AODV, DSDV, and DSR which is found as a research trend in majority of the literature archives. A brief observation of the study on advantages and disadvantages of various routing protocols is shown in Table 4

Table 4: Advantage and Disadvantage of routing protocols

\begin{tabular}{|c|l|l|l|}
\hline & \multicolumn{1}{|c|}{ Proactive } & \multicolumn{1}{c|}{ Reactive } & \multicolumn{1}{c|}{ Hybrid } \\
\hline Merit & $\begin{array}{l}\text {-Good } \\
\text { Availability of } \\
\text { information. } \\
\text {-Minimized } \\
\text { Latency }\end{array}$ & $\begin{array}{l}\text {-Availability } \\
\text { of route } \\
\text {-Loop free }\end{array}$ & $\begin{array}{l}\text {-appropriate } \\
\text { for large } \\
\text { network }\end{array}$ \\
\hline Demerit & $\begin{array}{l}\text { Overhead is high, } \\
\text { Routing } \\
\text { information is } \\
\text { flooded in the } \\
\text { whole network }\end{array}$ & $\begin{array}{l}\text { Increased } \\
\text { Latency }\end{array}$ & $\begin{array}{l}\text {-Increased } \\
\text { Complexity }\end{array}$ \\
\hline
\end{tabular}


Owing to inherent property of dynamic topology in mobile adhoc network, it can be seen that routing table is one of the most challenging problem. Each of the studies discussed in this paper has used different routing protocols, which have their own advantages as well as disadvantages. It can be significantly said that there are very few studies in the literature that has effectively addressed routing overhead issues as well as chooses to adopt signal strength for enhancing routing performance. In last 10 years, there are only 53 journals or transaction papers published in IEEE and only 27 in since 2010 till 2014 (till date) pertaining to keyword Routing Overhead in mobile adhoc network. And there exist only 5 journals or transaction papers in IEEE from 2000 till 2014 to find the usage of signal strength in mobile adhoc network for the purpose of routing. The statistics of the journal publications are more or less the same in Springer, ACM, and Elsevier. But, it has been choosen not to use all the filtered papers as majority of them are not related to the routing. Hence, it is a clear indication that studies done in the enhancing the routing protocol is still unsolved and is open issues when associated with routing overhead and adoption of signal strength.

\section{CONCLUSION}

There are massive archives of survey papers available in the digital library and other internet-based resources related to the efficient routing protocols in mobile adhoc network. This paper has investigated the pattern of almost all the available survey papers and found that $99 \%$ of the survey papers available are almost seems to be a repeat copy of each other. Hence, we have attempted to depict the information in little unique fashion, where the focus is majorly on understanding the effectiveness of prior researchers. The paper has briefly discussed about the 3 significant taxonomies of routing protocols in mobile adhoc network and discussed the frequently adopted evaluation parameters by prior researchers. The study has also reviewed all the significant work being done to address routing overhead and adoption of signal strength for enhancing routing behavior. Finally, the studies have chalked out research gap from the existing literature, which will assist the readers and future researchers to understand the potential benefits and limitations of the techniques evolved till date. Therefore, our future work will be in the direction of designing a framework of novel routing protocol for the purpose of minimizing the overhead caused owing to routing phenomenon in presence of dynamic topology in mobile adhoc network and check for utilization of signal strength in enhancing routing behavior.

\section{REFERENCES}

[1] http://tools.ietf.org/wg/manet/

[2] Raut, R., Thakare, P., Bhoyar, R.2014. Conspectus of Various Routing Protocols in VANET. International Journal of Advent Research in Computer \& Electronics, Vol.1, No.2

[3] https://datatracker.ietf.org/doc/rfc3561/

[4] http://www.ietf.org/rfc/rfc4728.txt

[5] http://tools.ietf.org/html/rfc6126

[6] http://tools.ietf.org/html/draft-ietf-manet-zone-zrp-00

[7] La, R.J., Seo, E.2011. Expected Routing Overhead for Location Service in MANETs Under Flat Geographic Routing. IEEE Transactions On Mobile Computing

[8] ER, I.I., Seah, W. K.G.2010. Adaptive Cluster-based Approach for Reducing Routing Overheads in MANETs. 16th Asia-Pacific Conference on Communications
[9] Jacquet, P., Viennot, L.2000. Overhead in Mobile Ad-hoc Network Protocols. INRIA Research Report

[10] Manjula.R, Santhosh.R. 2014. Reducing Routing Overhead In Manet Using Ncpr Protocol. International Journal of Innovative Research in Computer and Communication Engineering, Vol.2, Issue. 1

[11] Sekhar, P. C., Kumar, M.R.P., Kumar, B.P., Koteswararao, C.2013. Impact of Routing Overhead in A Real-Time MANET Environment. International Journal. Computer Technology \& Applications, Vol. 4, Iss.2 , pp.257-263

[12] Preetha, K.G., Unnikrishnan, A., Jacob, K.P.2012. A probabilistic approach to reduce the route establishment overhead in AODV algorithm for MANET. International Journal of Distributed and Parallel Systems, Vol.3, No.2

[13] Yadav, P., Saxena, S. 2014. Performance Analysis of QOS Issues on AODV \& OLSR Routing for MANETs Applications Using NS-3 Simulator. International Journal of Inventive Engineering and Sciences, Vol.2, Iss.2

[14] Patil,V.T., Dandannavar, P.S.2013. A Novel Rebroadcast Technique for Reducing Routing Overhead In Mobile Ad Hoc Networks. IOSR Journal of Computer Engineering, Vol.12, Iss.6, pp.01-09

[15] Sindhuja, S., Vidhya, S.2014. Enabling Efficient Rebroadcast For Reducing Routing Overhead In Manets. International Journal Of Technology Enhancements And Emerging Engineering Research, Vol 2, Iss.6

[16] Kure, N.D., Jain, S.A.2014. Minimum Overhead Routing Protocol in MANET. International Journal of Advance Foundation and Research in Computer, Vol.1, Iss.5.

[17] Manjhi, N., Patel, N.2012. Signal Strength Based Route Selection in MANETs. International Journal of Computer Science and Telecommunications, Vol.3, Iss.7

[18] Srinivasan, P., Kamalakkannan, K.2012. Signal Strength and Energy Aware Reliable Route Discovery in MANET. International Journal of Communication Network Security, ISSN: $2231-1882$, Vol.1, Iss.4

[19] Chin,K-W., Judge, J., Williams, A., Kermode, R.2002. Implementation Experience with MANET Routing Protocols. ACM SIGCOMM Computer Communications Review, Vol.32, No. 5

[20] Muthusenthil,B., Murugavalli, S.2014. The impact of location based attacks on geographical routing protocols. Journal of Theoretical and Applied Information Technology, Vol. 60, No.2

[21] Lu, X., Hui, P., Towsley, D., Pu, J., Xiong, Z.2010. Antilocalization anonymous routing for Delay Tolerant Network. Computer Networks-Elsevier, Vol. 54,pp. 18991910

[22] Hajj, W. E., Trabelsi, Z., Kountanis, and D.2007.Fast distributed dominating set based routing in large scale MANETs. SciemceDirect-Elsevier, Vol.30 pp.2880-2891

[23] Cardei, M., Cheng, X., Cheng, X., Du, D-Z.2005. Connected Domination in Multihop Ad Hoc Wireless Networks. INFOCOM

[24] Alzoubi, K. M., Wan, P-J., Frieder, and O.2002. New Distributed Algorithm for Connected Dominating Set in Wireless Ad Hoc Networks. IEEE-Proceedings of the 35th Hawaii International Conference on System Sciences 
[25] Haladkar, J. P., Patil, J.K.2014. Spectrum Aware PSNR Based Hand-off for Seamless Multimedia Streaming in Dense MANET. International Journal of Advanced Research in Computer Engineering \& Technology, Vol.3, Iss. 8

[26] Khalfallah, S., Ducourthial, B.2010. Bridging the Gap between Simulation and Experimentation in Vehicular Networks. In Vehicular Technology Conference Fall, IEEE 72nd, pp. 1-5

[27] Djahel, S., and Doudane, Y. G.2012. A Robust Congestion Control Scheme for Fast and Reliable Dissemination of Safety Messages in VANETs. IEEE Wireless Communications and Networking Conference, pp. 2264 2269

[28] Bhanumathi, V., Dhanasekharan, R.2012.RSS based Energy Efficient Scheme for the Reduction of Overhearing and Rebroadcast for MANET. ScienceDirect-Elsevier, vol.38, pp.2463-2472

[29] Lim, S., Yu, C., Das, C.R.2009. RandomCast: An EnergyEfficient Communication Scheme for Mobile Ad Hoc Networks", IEEE Transactions on Mobile Computing, Vol.8, Iss.8, pp.1039-1051

[30] Mukilan, P., \& Wahi, A.2012. EENMDRA: Efficient Energy and Node Mobility based Data Replication Algorithm for MANET. International Journal of Computer Science Issues, Vol. 9, Issue. 3, No. 1

[31] Vu, T.K., and Kwon, S.2014. Mobility-Assisted on-Demand Routing Algorithm for MANETs in the Presence of Location Errors. Hindawi Publishing Corporation
[32] Poma, L.P.P., Marcondes, C. A. C., Senger, H., Arantes, L.2014. Applying Machine Learning to Reduce Overhead in DTN Vehicular Networks. SBRC

[33] Yang,X., Li, L., Fan, X.2014. A Group mobility oriented History information based Light Location Service. International Journal of Smart Home, Vol.8, No.3, pp.33-48

[34] Mezher, A.M., Barba, C. T., Aguiar, L. U.2011. Optimized Path Selection in a Game-Theoretic Routing Protocol for Video-Streaming Services over MANETs. ACM Digital Library

[35] Kiwior, D., and Lam, L.2007.Routing Protocol Performance over Intermittent Links. IEEE Military Communication Conference

[36] Xu, H., Wu, X., Sadjadpour, H. R.2010. A Unified Analysis of Routing Protocols in MANETs. IEEE Transactions on communications, Vol. 58, No. 3

[37] Correiaa, F., Vazao, T.2010. Simple Ant Routing Algorithm strategies for a (Multipurpose) MANET model. ScienceDirect, Elsevier, Vol. 8, Issue. 8, pp. 810-823

[38] Liu, S., Cheng, L.2007. Local Tree Based Geometric Routing. IEEE Communications Society

[39] Quispe, L. E., Galan, L. M.2013. Behavior of Ad Hoc routing protocols, analyzed for emergency and rescue scenarios, on a real urban area. Expert Systems with Applications, Elsevier

[40] Ghosh, J., Philip, S.J., Qiao, C.2007. Sociological orbit aware location approximation and routing (SOLAR) in MANET. Science Direct, Elsevier 